\title{
Denosumab in the treatment of hypercalcemia secondary to malignancy
}

This article was published in the following Dove Press journal:

Orphan Drugs: Research and Reviews

23 November 2015

Number of times this article has been viewed

\author{
Alan C Dalkin' \\ Mitchell H Rosner ${ }^{2}$ \\ 'Division of Endocrinology and \\ Metabolism, ${ }^{2}$ Division of Nephrology, \\ University of Virginia Health System, \\ Charlottesville, VA, USA
}

\begin{abstract}
Hypercalcemia secondary to malignancy is associated with serious morbidity and mortality. Current treatment paradigms focus on acute lowering of serum calcium with a combination of intravenous volume repletion and expansion coupled with therapies to decrease bone release of calcium (calcitonin, bisphosphonates). While highly effective, in some cases, patients may be refractory to these existing therapies or may not tolerate them. Recently, the role of receptor activator of nuclear factor- $\mathrm{\kappa B}$ ligand in bone modeling has been elucidated and specific therapies to target this pathway have been developed. One of these therapies, denosumab has been effectively used in the management of postmenopausal osteoporosis. Given the important role of bone modeling in the development of malignancy associated hypercalcemia, denosumab has been used to treat this condition. This review focuses on the existing clinical data regarding denosumab for the treatment of hypercalcemia of malignancy.
\end{abstract}

Keywords: denosumab, hypercalcemia, malignancy, therapy

\section{Introduction}

It has been estimated that hypercalcemia (usually defined as a serum calcium level of $>10.5 \mathrm{mg} / \mathrm{dL}$ when corrected for serum albumin, or an ionized serum calcium above $5.1 \mathrm{mg} / \mathrm{dL}$ ) occurs in up to $30 \%$ of patients at some point during their battle with cancer. ${ }^{1-3}$ When hypercalcemia does occur, it is generally in those patients with much more advanced disease and is associated with a limited lifespan. ${ }^{1-3}$ Treatment of hypercalcemia of malignancy has traditionally focused on two phases: 1) the acute lowering of the serum calcium with alleviation of associated symptoms and 2) chronic therapy to allow maintenance of normal serum calcium levels. Although these treatments are generally effective, there are limitations to all current therapies and a small group of patients may remain refractory with continued hypercalcemia. Most recently, denosumab has been proposed as a potential therapy for both the acute and chronic management of malignancy-associated hypercalcemia. In this review, we will focus on the epidemiology, pathophysiology, and current treatment paradigms for malignancyassociated hypercalcemia with a detailed focus on the emerging role of denosumab.

\section{Epidemiology}

Although the most common cause of hypercalcemia in the ambulatory, asymptomatic patient is primary hyperparathyroidism, as mentioned previously, hypercalcemia is typically a late manifestation of numerous cancers (both solid and hematological). In a recent large cohort study, $3 \%$ of all patients were hypercalcemic and there was a striking association with the levels of serum calcium and risk for an underlying malignancy. ${ }^{4}$
Correspondence: Mitchell H Rosner Division of Nephrology, University of Virginia Health System, Box 800133 Charlottesville, VA 22908, USA

Fax + I 4349245848

Emailmhr9r@virginia.edu 
For male patients with a serum calcium of $>12 \mathrm{mg} / \mathrm{dL}$, the positive predictive value of cancer was $50 \%$, but even lower levels of hypercalcemia were associated with a high risk for cancer. ${ }^{4}$ However, for female patients, the positive predictive value of serum calcium $>12 \mathrm{mg} / \mathrm{dL}$ for cancer was much lower at $16.7 \%$ and lower levels of hypercalcemia did not have as striking a risk for cancer as in males. In men, the most prevalent cancers were lung (34\% of total), prostate (21\%), myeloma, colorectal, and other hematological cancers ( $8 \%$ each). Twelve other cancers made up the rest of the cases demonstrating the broad types of malignancies that can be associated with hypercalcemia. ${ }^{4}$ In women, the most prevalent cancer types were myeloma (24\%), breast (18\%), other hematological cancers (10\%), lung ( $8 \%)$, and metastatic cancer with unknown primary $(8 \%)$. There were 16 other cancers making up the rest of the cases $(32 \%)$. There was no difference between the calcium levels in the different types of cancer etiologies. Overall, most studies support the finding that squamous cell carcinoma of the lung is the most common type of cancer associated with hypercalcemia with up to $20 \%$ of these patients demonstrating hypercalcemia at some point during their course..$^{5-7}$ The next most common group of cancers associated with hypercalcemia are adenocarcinomas followed by hematological malignancies. ${ }^{7}$

The mortality associated with malignancy-associated hypercalcemia is typically high and reflective of advanced cancer at the time of diagnosis. For instance, in a recent study the median survival for patients with hypercalcemia secondary to a solid organ malignancy was only 52 days. ${ }^{7}$ However, the median survival for hypercalcemia secondary to a hematological malignancy is significantly higher at 362 days. ${ }^{7}$ In another recent study of 4,874 patients with malignancy associated hypercalcemia, the in-hospital mortality rate was $6.8 \%{ }^{8}$

\section{Pathophysiology of malignancy- associated hypercalcemia} Normal calcium homeostasis

Normal calcium homeostasis is maintained through a complex interplay between bone, the gastrointestinal tract, the kidney, and parathyroid glands with the major effector hormones of parathyroid hormone (PTH), vitamin D and, in a lesser role, calcitonin. Calcium levels (normal range $8.2-10.2 \mathrm{mg} / \mathrm{dL}$; 2.1-2.5 $\mathrm{mmol} / \mathrm{L}$ ) are maintained in the normal range largely through the pleiotropic actions of PTH. PTH acts in the kidney to stimulate conversion of 25-hydroxyvitamin D to the active form, 1,25-dihydroxyvitamin $\mathrm{D}$, which in turn acts to increase intestinal absorption of dietary calcium as well as affect bone release of calcium. PTH also has direct effects on the kidney tubules to stimulate reabsorption of calcium in the thick ascending limb of the loop of Henle while at the same time inhibiting phosphate reabsorption. ${ }^{9}$ Finally, PTH has significant regulatory effects on bone osteoblasts, and indirectly on osteoclasts, with the net result of bone calcium release. Mechanistically, PTH activates cells of the osteoblast lineage to produce receptor activator of nuclear factor- $\mathrm{KB}$ (RANK) ligand (RANKL) while at the same time decreasing the levels of osteoprotegerin (a competitive inhibitor of RANKL) leading to the maturation of osteoclasts and net bone resorption. ${ }^{9}$ Facilitating the role of PTH to stimulate bone resorption are the actions of 1,25-dihydroxyvitamin $\mathrm{D}$, which acts through its nuclear receptor to trigger osteoclast genesis. Thus, the concerted actions of PTH and 1,25-dihdroxyvitamin D act to increase serum calcium, in large part through their effects on bone release of calcium.

\section{Hypercalcemia of malignancy}

In the setting of certain cancers, the normal regulatory physiology controlling calcium homeostasis can be upset leading to significant, symptomatic hypercalcemia. The major etiologies and mechanisms of malignancy-associated hypercalcemia are shown in Table $1 .{ }^{10}$ It is critical to note that, except in the instances of ectopic activation of vitamin D stores, a common feature of all these mechanisms is the primacy of bone calcium release.

The most common etiology of malignancy associated hypercalcemia is due to the excessive production of parathyroid hormone-related protein (PTHrP) (also termed humoral hypercalcemia of malignancy). PTHrP is a very similar peptide

Table I Etiologies of malignancy-associated hypercalcemia

\begin{tabular}{|c|c|c|c|c|}
\hline Mechanisms of hypercalcemia & Frequency (\%) & Bone metastases & Pathogenesis & Typical tumors \\
\hline Local osteolytic & 20 & Extensive & Cytokines, chemokines, PTHrP & Breast and lung cancer, myeloma \\
\hline $\begin{array}{l}\text { Humoral hypercalcemia of malignancy } \\
(\mathrm{HHM}) \text { or PTHrP mediated }\end{array}$ & 80 & Minimal or absent & PTHrP & $\begin{array}{l}\text { Squamous cell cancers, renal cancer, } \\
\text { ovarian cancer, breast cancer }\end{array}$ \\
\hline $\begin{array}{l}\text { I,25 }(\mathrm{OH})_{2} \text {-vitamin D secreting } \\
\text { lymphomas }\end{array}$ & $<1$ & Variable & $\mathrm{I}, 25(\mathrm{OH})_{2}$-vitamin D & Lymphoma \\
\hline
\end{tabular}

Note: Reprinted with permission from Lamiere N, Van Biesen W, Vanholder R. Electrolyte disturbances and acute kidney injury in patients with cancer. Semin Nephrol. 2010;30:534-547. ${ }^{10}$ Copyright (C) 2010, with permission from Elsevier.

Abbreviation: PTHrP, parathyroid hormone related protein. 
to PTH and both activate the type I PTH/PTHrP receptor. ${ }^{11}$ Thus, PTHrP increases bone resorption via indirect activation of osteoclasts (through increased RANKL production and decreased production of osteoprotegerin) and increases renal reabsorption of calcium along with increases in renal phosphate excretion. ${ }^{11}$ However, PTHrP has minimal effects on increasing 1,25-dihydroxyvitamin $\mathrm{D}$ production and thus does not significantly affect intestinal calcium absorption. ${ }^{12,13}$ Indeed, in this setting, PTHrP-mediated hypercalcemia exerts feedback inhibition on PTH synthesis and secretion, which in turn reduces 1,25-dihydroxyvitamin $\mathrm{D}$ production and hence both 1,25-dihydroxyvitamin D and intestinal calcium absorption may be low normal or frankly below normal. Common solid tumors that ectopically produce PTHrP include breast, lung, head and neck, renal cell, bladder, pancreatic, hepatocellular, melanoma, and carcinoid. ${ }^{14}$ Hematological cancers associated with excess PTHrP include non-Hodgkin's lymphoma and T-cell leukemia/lymphoma associated with the human T-lymphotropic virus type $1 .{ }^{14}$ In some cases, there are tumor-associated changes that can amplify the production of PTHrP. ${ }^{15,16}$ For instance, in breast cancer, the calcium sensing receptor that normally would decrease $\mathrm{PTH}$ production in the parathyroid gland in response to elevations in serum calcium is activated so that high calcium levels actually stimulate PTHrP production in a vicious cycle that leads to rises in serum calcium. ${ }^{15,16}$

The next most common mechanism of malignancy associated hypercalcemia is that due to local osteolysis. ${ }^{17}$ In these circumstances, the malignancy interacts with bone to lead to the release of calcium in excess of the ability of the kidneys to excrete it. Common examples of such cancers include multiple myeloma and metastatic adenocarcinomas (lung and breast). These cancers can lead to the paracrine secretion of osteoclast activating factors such as interleukin-6, RANKL, interleukin-3, and even local PTHrP production. ${ }^{18,19}$ It is these local factors and not bony destruction due to tumor infiltration that leads to the activation of osteoclasts and release of bone calcium.

In much less commonly encountered cases, certain cancers (most notably lymphomas) may have the ability to produce high levels of 1,25-dihydroxyvitamin D in a nonregulated fashion..$^{20,21}$ In this case, the high levels of active vitamin D stimulate increased gastrointestinal absorption of calcium as well as promote bone loss of calcium leading to rises in serum calcium. Interestingly, tissue macrophages, rather than actual tumor cells, may be the most likely ectopic source of this enzyme. ${ }^{21}$

Rarely, some malignancies have the ability to synthesize and secrete PTH itself as a means to cause hypercalcemia.
To date, case reports of lung cancers and prostate cancers have been associated with ectopic PTH-mediated hypercalcemia.

\section{The renal response to hypercalcemia}

Usually, the kidney is able to rapidly and effectively excrete an excess calcium load. When hypercalcemia occurs, the response is either inadequate (usually due to concomitant volume depletion) or the calcium load is so great as to overwhelm excretory capacity. In most cases, it is the former mechanism, which is operative and critical to the development of clinically apparent hypercalcemia. This is because elevated serum calcium levels lead to activation of the calcium-sensing receptor in the thick ascending limb of the loop of Henle, which inhibits the sodium/potassium/ chloride $(\mathrm{Na} / \mathrm{K} / 2 \mathrm{CL}$ or $\mathrm{NKCC} 2)$ cotransporter and leads to significant natriuresis and volume depletion. ${ }^{22}$ This may be exacerbated by hypercalcemia-induced nausea and vomiting and poor nutritional/fluid intake. Thus, volume depletion is a universal finding in patients with significant hypercalcemia and restoration of glomerular filtration rate is a critical aspect of therapy.

\section{Therapeutic approaches to malignancy-associated hypercalcemia} The therapy of malignancy-associated hypercalcemia typically follows a stepwise approach that focuses on rapid lowering of the serum calcium to alleviate symptoms followed by a more chronic therapy phase focused on prevention of recurrence (Table 2). If possible, definitive therapy of the underlying malignancy is critical but often the malignancy is very advanced at the time hypercalcemia presents and thus, therapy of hypercalcemia may be part of a more global palliative care effort.

\section{Step I: intravenous hydration}

Patients with hypercalcemia are volume depleted and a critical step in the treatment is to restore extracellular volume, improve renal perfusion, and glomerular filtration rate and thus increase renal excretion of calcium. Depending upon the individual patient and their presenting volume status as well as their cardiac performance, aggressive intravenous (IV) hydration with $0.9 \%$ normal saline (with an initial bolus of $1-2 \mathrm{~L}$ followed by an infusion of $200-250 \mathrm{~mL} /$ hour) is indicated and should not be delayed. Important caveats to this step are those patients who are in either acute oliguric kidney failure or have significant chronic kidney disease or end-stage renal disease where the fluid bolus cannot be tolerated and would lead to excessive and potentially dangerous volume overload. 
This is also the case for patients with compromised cardiac performance. In those circumstances, a loop diuretic can be added once volume status is corrected. However, recent data have given pause to the once routine use of loop diuretics to augment renal calcium excretion as there seems to be little benefit and potential harm. ${ }^{23}$ Finally, in those patients with either refractory oliguria (do not respond to a loop diuretic) or those with end-stage renal disease, the use of hemodialysis with a low calcium dialysate can be very effective. ${ }^{24}$

\section{Step 2: bisphosphonate therapy}

Currently, bisphosphonates are the cornerstone of the therapy for malignancy-associated hypercalcemia. They are highly effective agents that act on osteoclasts to decrease their recruitment, activity, and adhesion to the bone matrix..$^{25,26}$ In doing so, they significantly decrease the bone release of calcium. Currently, both pamidronate and zolendonate are approved by the US Food and Drug Administration for the treatment of malignancy-associated hypercalemia. A full discussion of the effects and use of these agents is beyond the scope of this review, but the reader is referred to Rosner and Dalkin ${ }^{2}$ as a comprehensive review on this subject. It is important to note that the drugs will lead to significant decreases in serum calcium over several days and have longer lasting effects up to months with single doses and can be given at regular intervals to prevent recurrence of hypercalcemia. Importantly, these drugs also have important and beneficial effects on the course of metastatic bone disease. ${ }^{27}$ Although these drugs are generally well tolerated, there are important short and long-term side effects. In the short term, there are infusionrelated side effects such as fever and electrolyte disturbances that are easily managed. ${ }^{28}$ Rarer, but very serious, toxicities include osteonecrosis of the jaw (usually associated with longer term use of bisphosphonates) and renal failure. The kidney manifestations include: 1) nephrotic range proteinuria with a histological pattern of collapsing and non-collapsing focal segmental glomerulosclerosis and 2) acute tubular necrosis. ${ }^{29,30}$ Thus, it is recommended that kidney function be closely monitored during therapy with these agents. A small percentage of patients with malignancy-associated hypercalcemia remain refractory to bisphosphonates and will require alternative approaches.

\section{Step $2 b$ : alternative approaches}

Several drugs are available either as add-ons to bisphosphonate therapy (such as calcitonin) or as therapies for patients that are refractory to bisphosphonates (gallium nitrate). ${ }^{31,32}$ These drugs have variable efficacy and in the case of gallium nitrate potentially serious toxicities that limit their widespread use. For certain malignancies such as lymphomas, where excessive 1,25 dihydroxyvitamin D production is critical in the pathogenesis of hypercalcemia, the use of corticosteroids may be effective. ${ }^{33}$

Given that these alternatives are less attractive and that there are patients who may either be refractory to bisphosphonates or have contraindications to their use, other therapies are needed to treat malignancy-associated hypercalcemia.

\section{Clinical perspective on therapeutic options and a potential role of denosumab}

We were asked to evaluate and assist in the management of an 80-year-old woman with severe hypercalcemia. The patient presented to the emergency department with several days of confusion, nausea, and vomiting. In the emergency department, she was found to have a serum calcium level of $16.5 \mathrm{mg} / \mathrm{dL}$, a serum creatinine of $5.8 \mathrm{mg} / \mathrm{dL}$, and a PTH level of $9 \mathrm{pg} / \mathrm{mL}$. Of note, the patient has a long history of poorly controlled type 2 diabetes mellitus, New York Heart Association grade 3 systolic heart failure, and stage 4 chronic kidney disease with a baseline serum creatinine of $2.3 \mathrm{mg} / \mathrm{dL}$. A chest X-ray revealed a large right upper lobe mass and a subsequent PTHrP returned elevated at $201 \mathrm{pmol} / \mathrm{L}$ (normal $<2.0 \mathrm{pmol} / \mathrm{L}$ ).

She was treated initially with IV $0.9 \%$ saline but after 1.5 L, she became increasingly short of breath necessitating cessation of IV fluids and an attempt was made to diurese her with IV furosemide. However, her urine output did not increase nor did her serum calcium fall. Thus, on hospital day $\# 1$, she underwent emergent hemodialysis with a low calcium dialysate. This was effective in acutely lowering her serum calcium to $12.9 \mathrm{mg} / \mathrm{dL}$, but more long-term therapy was needed. The options included: bisphosphonates, calcitonin, gallium nitrate, and the newer agent denosumab. Given the presence of significant kidney failure and concerns for the toxicity of these agents, denosumab at a dose of $120 \mathrm{mg}$, was initiated.

\section{Role of RANKL in bone remodeling}

As stated, the regulation of bone remodeling and turnover is complex and involves multiple signaling pathways from osteoblast to osteoclast and vice versa, as well as from other supporting cells such as bone marrow and stromal cells including cytokines and growth regulators. A key pathway in this cascade includes RANKL, produced primarily by cells of the osteoblast lineage, which mediates osteoclast activity 
via signaling through the RANK receptor on the osteoclast cell surface (both precursor and mature cells) (Figure 1). ${ }^{34}$ RANKL drives osteoclast differentiation and increases bone resorption, thereby releasing calcium and local growth factors into the bone microenvironment, and subsequently into the systemic circulation. Conditions of increased bone remodeling, such as in patients with primary hyperparathyroidism and in women after the menopause, are associated with an increased production of RANKL and osteoclast activity. It has been postulated that the presence of RANKL may also play a role in the development of skeletal metastases due to both direct and indirect changes in the bone microenvironment that favor malignant cell survival. ${ }^{35}$ Thus, pharmacologic manipulation of the RANKL/RANK signaling system has been explored as a means to alter physiologic and pathologic processes in bone.

\section{Denosumab as an inhibitor of RANKL}

Denosumab is a fully humanized monoclonal antibody that binds to and neutralizes RANKL (Figure 2). In so doing, osteoclast activity rapidly declines following treatment with denosumab with subsequent reduction in osteoblast cell activity, likely related to the reduction in osteoclast signals back to the osteoblast. ${ }^{36}$ In postmenopausal women, bone remodeling can drop by over $80 \%$ from baseline within weeks to months after treatment and will remain in a similar range as long as the denosumab is continued. Interestingly, upon discontinuation of denosumab, bone turnover transiently increases to levels above the starting range before eventually returning to pretreatment levels. ${ }^{37}$ This rebound phenomenon could suggest that production of RANKL is enhanced when signals to RANK are blocked, though the mechanism of that feedback relationship is not known.

Multiple lines of clinical evidence have suggested that denosumab could be helpful in the treatment of hypercalcemia, and in particular the hypercalcemia of malignancy. Treatment with denosumab is associated with hypocalcemia, though this is more common in the dosing regimens used for patients with malignancy. ${ }^{38}$ In patients treated for low or declining bone density (60 mg every 6 months), hypocalcemia can be seen in patients with concomitant vitamin D deficiency. In patients with cancer, phase III trials have documented an incidence of hypocalcemia of $\sim 10 \%$, roughly two-fold higher than with intravenous bisphosphonates. Similarly, in patients with solid tumors such as breast and prostate cancers, as well as multiple myeloma, the development of hypercalemia (along with a host of other skeletal-related events) is significantly delayed

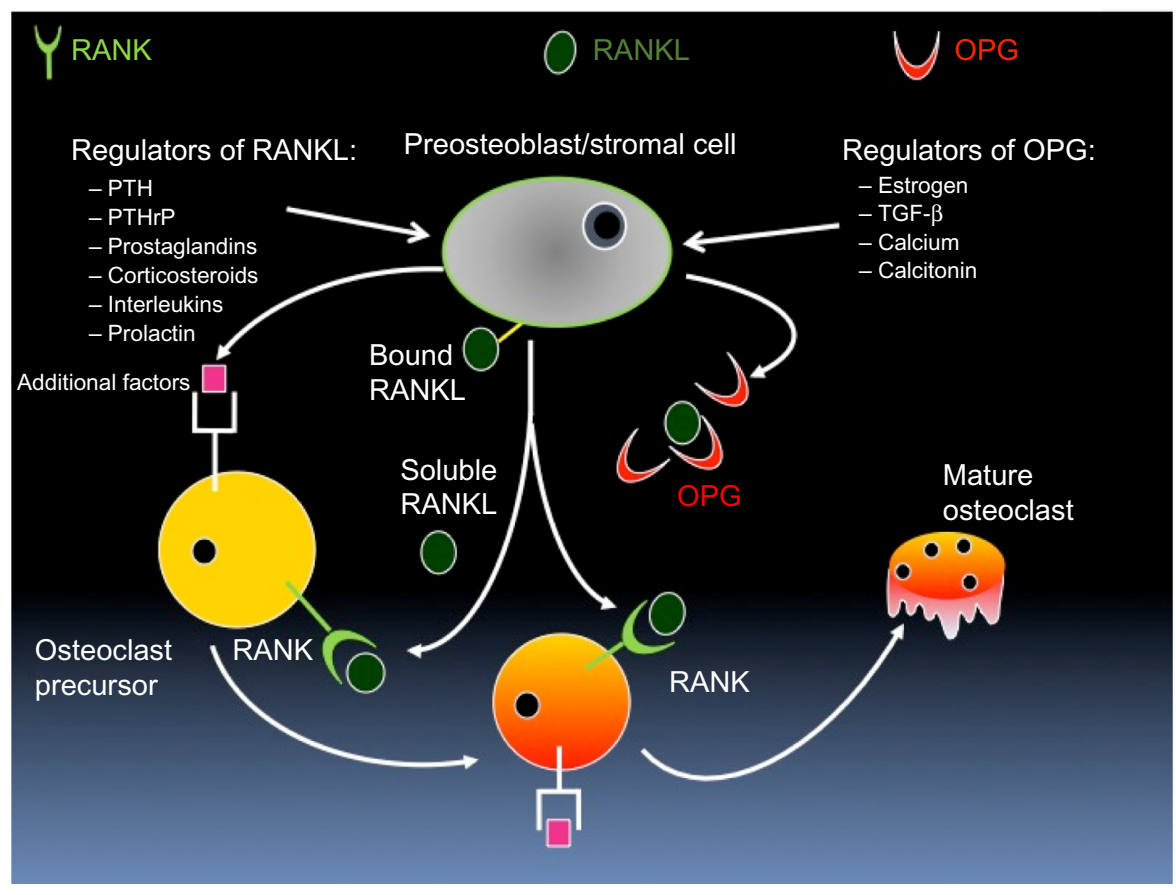

Figure I The role of RANKL in bone remodeling.

Notes: RANKL is produced by cells of the osteoblast lineage and, following binding to its receptor (RANK), RANKL drives osteoclast development. The decoy receptor, OPG, binds to RANKL and prevents it from stimulating osteoclast cells. Numerous factors have been proposed to regulate the production of either RANKL or OPG to alter the balance of RANKL and OPG.

Abbreviations: OPG, osteoprotegerin; PTH, parathyroid hormone; PTHrP, parathyroid hormone-related protein; RANK, receptor activator of nuclear factor-KB; RANKL, RANK ligand; TGF- $\beta$, transforming growth factor $\beta$. 


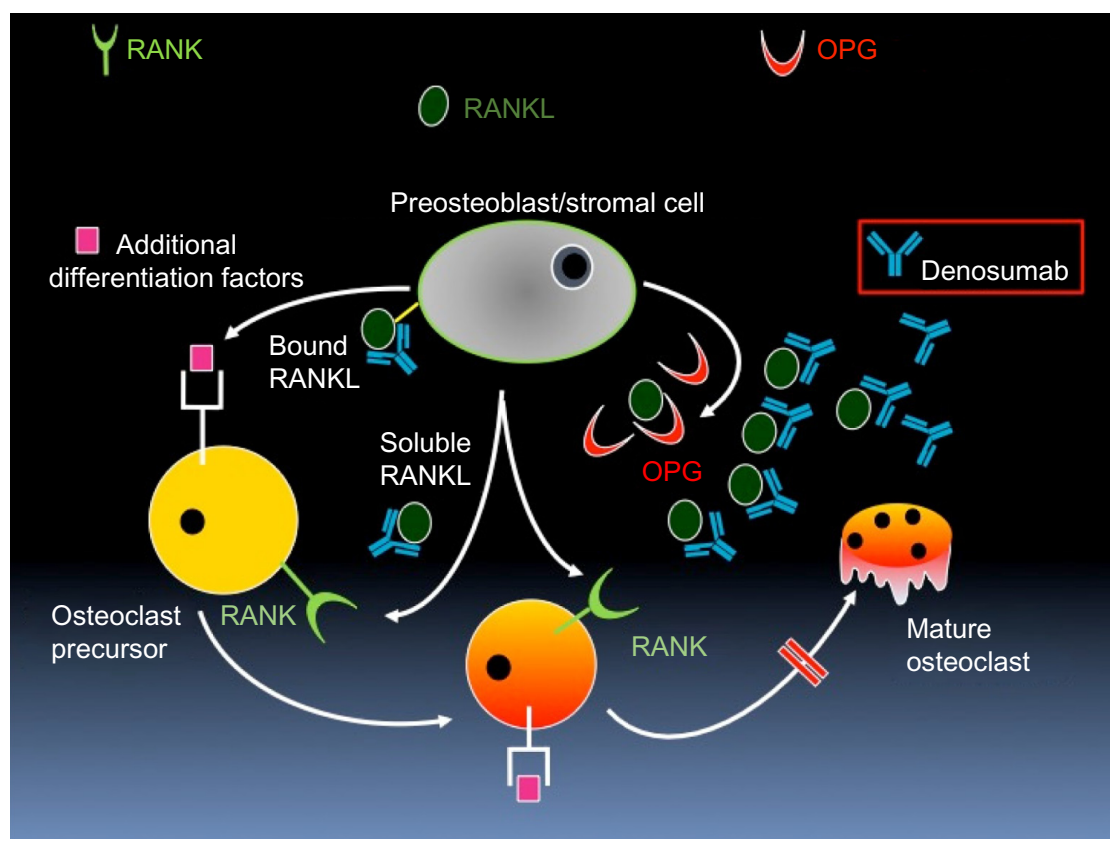

Figure 2 Mechanism of action of denosumab in RANKL signaling.

Notes: Denosumab binds to RANKL and prevents binding to RANK. Perhaps as a response to the reduced signal, osteoblast production of RANKL likely increases but the excess denosumab prevents RANKL binding to RANK, thereby reducing osteoclast activation (double red line).

Abbreviations: OPG, osteoprotegerin; RANK, receptor activator of nuclear factor-KB; RANKL, RANK ligand.

by the use of denosumab. ${ }^{38}$ Giant cell tumor of bone is one of the more common benign tumors of bone, but a small subset of patients experience a more aggressive clinical course with aggressive and metastatic disease process. Adjuvant therapy with denosumab has been explored in recent clinical trials. Interestingly, discontinuation of denosumab was associated with the development of hypercalcemia in one such patient and other modalities of treatment of the hypercalcemia were ineffective. ${ }^{39}$ Treatment with denosumab was resumed with subsequent control of the hypercalcemia. Hypercalcemia in other clinical syndromes (eg, fibrous dysplasia) has been reported to respond in a similar fashion. ${ }^{40}$

In addition, there are safety factors that make the use of denosumab appealing for the management of hypercalcemia. ${ }^{38}$ As evidenced by our case presentation, patients with marked hypercalcemia have some concomitant aspect of renal insufficiency, either via dehydration related to fluid depletion (eg, from nephrogenic diabetes insipidus) or direct renal toxicity from the hypercalcemia itself (eg, nephrocalcinosis). Denosumab is eliminated by mechanisms independent of either renal or hepatic clearance, and hence dose adjustment is not needed in the face of a reduced estimated glomerular filtration rate, though safety data in severe renal dysfunction are lacking. Small trials in patients with severely reduced renal function have documented a potentially higher incidence of hypocalcemia following treatment with denosumab. . $^{41-43}$ This treatment approach contrasts that of other agents often employed in the treatment of severe hypercalcemia such as the intravenous bisphosphonates, which are contraindicated in patients with a creatinine clearance below $30 \mathrm{~mL} / \mathrm{min}$. In addition, clearance of denosumab is relatively slow and duration of action longer than with some of the intravenous bisphosphonates such as pamidronate and hence denosumab could potentially provide a longer period of time with lower calcium concentrations than other standard treatment options.

Other side effects and possible complications from denosumab remain a concern. There is a potential for perturbation of immune function following denosumab as subsets of $\mathrm{T}$ and B cells express RANKL. Some early trials have reported a higher incidence of cellulitis, but this relationship has not been supported by trials in patients with malignancy. ${ }^{44}$ Reports of osteonecrosis of the jaw and atypical fracture of the hip following longer term denosumab have been reported as well, though the incidence of either untoward complication does not seem greater than that observed following treatment with any of the bisphosphonates.

\section{Denosumab in the treatment of hypercalcemia of malignancy}

Within the past $12-18$ months, a number of smaller clinical trials and case reports have been published, each aimed at examining the utility of denosumab in the treatment of hypercalcemia. Most of these reports include patients 
Table 2 Therapeutic approach for malignancy-associated hypercalcemia

\begin{tabular}{|c|c|c|c|}
\hline Step & Agents & Efficacy & Concerns \\
\hline $\begin{array}{l}\# \mathrm{I} \text { : Aggressive volume repletion to } \\
\text { improve renal function and aid excretion } \\
\text { of excess calcium (acute phase) } \\
\text { \#Ib: If not tolerated, dialysis with low } \\
\text { calcium dialysate can be used }\end{array}$ & $\begin{array}{l}\text { IV fluids ( } 0.9 \% \text { saline) } \\
\text { Loop diuretic only added if } \\
\text { volume overload is present } \\
\text { Hemodialysis with low } \\
\text { calcium dialysate }\end{array}$ & $\begin{array}{l}\text { Acutely effective but requires follow- } \\
\text { up with definitive therapy } \\
\text { Highly effective but requires follow- } \\
\text { up with definitive therapy }\end{array}$ & $\begin{array}{l}\text { Patients with oliguria, end-stage } \\
\text { renal disease or heart failure } \\
\text { may not tolerate fluid load. Loop } \\
\text { diuretics may lead to other } \\
\text { electrolyte abnormalities } \\
\text { Invasive procedure requiring } \\
\text { dialysis catheter placement }\end{array}$ \\
\hline $\begin{array}{l}\text { \#2 Bisphosphonate therapy to decrease } \\
\text { bone release of calcium } \\
\text { \#2b: Adjunctive or alternative agents } \\
\text { such as calcitonin, gallium nitrate or } \\
\text { corticosteroids }\end{array}$ & $\begin{array}{l}\text { Pamidronate, zolendronate } \\
\text { lbandronate (not FDA } \\
\text { approved for this indication) } \\
\text { Calcitonin } \\
\text { Gallium nitrate } \\
\text { Corticosteroids }\end{array}$ & $\begin{array}{l}\text { Very effective in majority of patients } \\
\text { and effects can last several weeks } \\
\text { and can be chronically repeated to } \\
\text { control serum calcium. Also effective } \\
\text { in decreasing bone metastases } \\
\text { Synergistic effect with bisphosphonates } \\
\text { but short-lived and modest response } \\
\text { Effective second-line agent } \\
\text { Useful for some lymphoid cancers } \\
\text { overproducing vitamin D }\end{array}$ & $\begin{array}{l}\text { Small percentage of patients will } \\
\text { not respond. Infusion-related } \\
\text { side effects, osteonecrosis and } \\
\text { nephrotoxicity may limit use in } \\
\text { some patients } \\
\text { Short-lived and low efficacy overall } \\
\text { Anemia and acute kidney injury } \\
\text { can occur } \\
\text { Limited spectrum of efficacy }\end{array}$ \\
\hline \#3 RANKL inhibitors & Denosumab & $\begin{array}{l}\text { Limited data but appears effective } \\
\text { and can be given to patient with renal } \\
\text { failure }\end{array}$ & $\begin{array}{l}\text { Concern for immune-related } \\
\text { effects, osteonecrosis has been } \\
\text { reported }\end{array}$ \\
\hline
\end{tabular}

Abbreviations: IV, intravenous; RANKL, receptor activator of nuclear factor- $\kappa B$ ligand; FDA, US Food and Drug Administration.

having recently received intravenous bisphosphonates as standard of care, though inclusion criteria generally include sufficient time to categorize the patients as non-responders to that intervention. Hu et al conducted a single arm study treating 33 patients having hypercalcemia of malignancy (corrected serum calcium $>12.5 \mathrm{mg} / \mathrm{dL}$ ) including both solid and hematologic tumors with denosumab $(120 \mathrm{mg}$ subcutaneously on days $1,8,15,29$, and every 4 weeks thereafter). ${ }^{45}$ Following two injections of denosumab, $64 \%$ of patients achieved corrected calcium levels of $\leq 11.5 \mathrm{mg} / \mathrm{dL}$ and $36 \%$ reached calcium levels of $\leq 10.8 \mathrm{mg} / \mathrm{dL}$. Over the course of the study, $70 \%$ of patients responded with a drop in calcium and $64 \%$ had a complete response. As the time between denosumab treatments lengthened, return of hypercalcemia was seen in $30 \%$ of patients, though subsequent doses of denosumab remained effective. Of patients reporting symptoms of hypercalcemia at the outset of the trial, roughly half had improvement or resolution. In terms of biochemical parameters, markers of bone turnover dropped by $\sim 80 \%$ within 10 days. Nearly all patients experienced an adverse event during the 2 -month trial, though only $39 \%$ of adverse events were felt related to the denosumab. Most common was hypophosphatemia and nausea. Despite the substantial dosing of denosumab, no instances of hypocalcemia were reported. The patients in this study were extremely ill as the estimated median survival of those enrolled was 71 days.

Dietzek et al conducted a retrospective chart review of patients at The Brigham and Women's Hospital who were treated with denosumab for hypercalcemia of malignancy. ${ }^{46}$
Seven patient records were analyzed representing a variety of diagnoses including multiple myeloma, non-Hodgkin's lymphoma, sarcoma, and cancer of unknown primary. In comparison with the trial reported above, ${ }^{45}$ patients in this series received only a single dose of denosumab, either $60 \mathrm{mg}$ (two patients) or $120 \mathrm{mg}$ (five patients) administered within 2 weeks of admission. Six of the seven patients also received an intravenous bisphosphonate before the denosumab. As with the Hu study, these patients were gravely ill with the median survival for those five patients that expired being 26 days from administration of denosumab. All patients saw a reduction in the corrected calcium levels with one patient who received a $60 \mathrm{mg}$ dose, developing hypocalcemia 86 hours after treatment.

Adhikaree et al recently reported the treatment of a 66-year-old patient with ovarian cancer and hypercalcemia of malignancy resistant to intravenous bisphosphonates, with denosumab (dose not specified) for three doses ${ }^{47}$ The patient experienced a rapid decline in calcium levels following each dose. After the third dose, the patient became hypocalcemic and required hospitalization to provide clinical stabilization. The authors proposed that denosumab should be used with caution in these patients. Potentially, patients with advanced stages of malignancy may have suboptimal nutrition and diminished intake of calcium and/or vitamin D. Simultaneous reductions in bone turnover and calcium absorption could result in significant hypocalcemia. This explanation remains speculative as assessment of vitamin $\mathrm{D}$ stores and calcium intake are not included in most of these cases. Nonetheless, taken together with a similar caution from Health 
Canada which issued a MedEffect ${ }^{\mathrm{TM}}$ in 2012, providers using denosumab for patients with difficult to treat hypercalcemia should remain vigilant for subsequent hypocalcemia due to its potency in reducing calcium mobilization from bone.

Recently, three case reports of patients with parathyroid cancer treated with denosumab were published. In one instance, a patient with widely metastatic disease who had required repeated admissions for hypercalcemic crisis was initially treated with the intravenous bisphosphonate pamidronate and the oral calcium receptor mimetic cincalcet without response. In contrast, administration of a single dose (120 mg) of denosumab resulted in a precipitous drop in calcium within 72 hours. The patient had concomitant vitamin D deficiency due to the hyperparathyroidism and hence developed hypocalcemia following denosumab, thereby requiring treatment with cholecalciferol. The duration of follow-up for this patient was 3 months, during which time calcium levels remained stable without return of hypercalcemia. ${ }^{48}$ Serum PTH levels and bone turnover markers following denosumab treatment were not included in the report. In the second case, a 71-year-old man with metastatic parathyroid carcinoma was treated with a combination of denosumab and cinacalcet (a calcium sensing receptor mimetic) for nearly 1 year. ${ }^{49}$ Finally, a 50-year-old man with parathyroid carcinoma, who responded poorly to bisphosphonates and who was unable to tolerate cinacalcet, was treated with monthly denosumab (120 mg subcutaneously) and thereafter experienced a slow decline in calcium levels though the patient remained hypercalcemic. ${ }^{50}$ Thus, the use of denosumab in PTH-mediated hypercalcemia may have substantial efficacy.

\section{Conclusion}

The causes of hypercalcemia in patients with underlying malignancy include an array of pathologic processes from enhanced absorption via inappropriate activation of vitamin D to accelerated bone resorption due to local and/ or systemic factors. In either scenario, fluid resuscitation and enhanced renal excretion of excess calcium remain a mainstay of therapy. For patients with excess bone resorption, currently approved treatment regimens may not always be sufficient to restore safe, or normal, calcium concentrations. Denosumab, a potent antiresorptive agent, appears to have promise as an additional tool in the armament of treatment for patients with sustained hypercalcemia. These patients are often quite ill and have a poor prognosis, so management of complications is an important aspect in providing a better quality of life. Denosumab can be employed in the face of either renal or hepatic dysfunction in contrast to the intravenous bisphosphonates and thereby expanding the range of potentially treated individuals. Although there remains no set regimen that is generally effective, repeated doses can be given at regular intervals. Hypocalcemia remains the greatest risk in some patients, though attempts to enhance calcium and vitamin D intake after improvement in the initial hypercalcemia could be a strategy to minimize that complication.

\section{Disclosure}

The authors report no conflicts of interest in this work.

\section{References}

1. Stewart AF. Clinical practice. Hypercalcemia associated with malignancy. N Engl J Med. 2005;352(4):373-379.

2. Rosner MH, Dalkin AC. Onco-nephrology: the pathophysiology and treatment of malignancy-associated hypercalcemia. Clin J Am Soc Nephrol. 2012;7(10):1722-1729.

3. Vassilopoulou-Sellin R, Newman BM, Taylor SH, Guinee VF. Incidence of hypercalcemia in patients with malignancy referred to a comprehensive cancer center. Cancer. 1993;71(4):1309-1312.

4. Hamilton F, Carroll R, Hamilton W, Salisbury C. The risk of cancer in primary care patients with hypercalcemia: a cohort study using electronic records. Br J Cancer. 2014;111:1410-1412.

5. Pelosof LC, Gerber DE. Paraneoplastic syndromes: an approach to diagnosis and treatment. Mayo Clin Proc. 2010;85:838-854.

6. Mazzone PJ, Arroliga AC. Endocrine paraneoplastic syndromes in lung cancer. Curr Opin Pulm Med. 2003;9:313-320.

7. Donovan PJ, Achong N, Griffin K, Galligan J, Pretorius CJ, McLeod DS. PTHrP-mediated hypercalcemia: causes and survival in 138 patients. J Clin Endocrinol Metab. 2015;100(5):2024-2029.

8. Wright JD, Tergas AI, Ananth CV, et al. Quality and outcomes of treatment of hypercalcemia of malignancy. Cancer Invest. 2015;33(8): 331-339.

9. Bringhurst D, Demay MB, Kronenberg HM. Hormones and disorders of mineral metabolism. In: Melmed S, Polonsky KS, Larsen PR, Kronenberg HM, editors. Williams Textbook of Endocrinology. 12th ed. St Louis, MO: WB Saunders; 2011:1237-1257.

10. Lamiere N, Van Biesen W, Vanholder R. Electrolyte disturbances and acute kidney injury in patients with cancer. Semin Nephrol. 2010;30: 534-547.

11. Strewler GJ. The physiology of parathyroid hormone-related protein. N Engl J Med. 2000;342(3):177-185.

12. Horwitz MJ, Tedesco MB, Sereika SM, et al. Continuous PTH and PTHrP infusion causes suppression of bone formation and discordant effects on 1,25(OH)2 vitamin D. J Bone Miner Res. 2005;20(1): 1792-1803.

13. Dean T, Vilardaga JP, Potts JT Jr, Gardella TJ. Altered selectivity of parathyroid hormone $(\mathrm{PTH})$ and $\mathrm{PTH}$-related protein $(\mathrm{PTHrP})$ for distinct conformations of the PTH/PTHrP receptor. Mol Endocrinol. 2008;22(1):156-166.

14. Wysolmerski JJ. Parathyroid hormone-related protein: an update. J Endocrinol Metab. 2012;97(9):2947-2956.

15. Akhtari M, Mansuri J, Newman KA, Guise TM, Seth P. Biology of breast cancer bone metastasis. Cancer Biol Ther. 2008;7(1):3-9.

16. Sanders JL, Chattopadhyay N, Kifor O, Yamaguchi T, Butters RR, Brown EM. Extracellular calcium-sensing receptor expression and its potential role in regulating parathyroid hormone-related peptide secretion in human breast cancer cell lines. Endocrinology. 2000;141(12): 4357-4364.

17. Reagan P, Pani A, Rosner MH. Approach to diagnosis and treatment of hypercalcemia in a patient with malignancy. Am J Kidney Dis. 2013; 63(1):141-147. 
18. Roodman GD. Mechanisms of bone lesions in multiple myeloma and lymphoma. Cancer. 1997;80(Suppl 8):1557-1563.

19. VanHouten JN, Yu N, Rimm D, et al. Hypercalcemia of malignancy due to ectopic transactivation of the parathyroid hormone gene. $J$ Clin Endrocrinol Metab. 2006;91(2):580-583.

20. Seymour JF, Gagel RF. Calcitriol: the major humoral mediator of hypercalcemia in Hodgkin's disease and non-Hodgkin's lymphoma. Blood. 1993;82(5):1383-1394.

21. Hewison M, Kantorovich V, Liker HR, et al. Vitamin D-mediated hypercalcemia in lymphoma: evidence for hormone production by tumoradjacent macrophages. J Bone Miner Res. 2003;18(3):579-582.

22. Toka HR, Al-Romaih, Koshy JM, et al. Deficiency of the calciumsensing receptor in the kidney cause parathyroid hormone-independent hypocalciuria. J Am Soc Nephrol. 2012;23(11):1879-1890.

23. LeGrand SB, Leskuski D, Zama I. Narrative review: furosemide for hypercalcemia: an unproven yet common practice. Ann Intern Med. 2008;149(4):259-263.

24. Cardella CJ, Brikin BL, Rapoport A. Role of dialysis in the treatment of severe hypercalcemia: report of two cases successfully treated with hemodialysis and review of the literature. Clin Nephrol. 1979;12(6): 285-290.

25. Major P, Lortholary A, Hon J, et al. Zolendronic acid is superior to pamidronate in the treatment of hypercalcemia of malignancy: a pooled analysis of two randomized, controlled clinical trials. J Clin Oncol. 2001;19(2):558-567.

26. Nussbaum SR, Younger J, Vanderpol CJ, et al. Single-dose intravenous therapy with pamidronate for the treatment of hypercalcemia of malignancy: comparison of 30-, 60- and 90-mg dosages. Am J Med. 1993;95(3):297-304.

27. Ibrahim T, Farolfi A, Mercatali L, Ricci M, Amadori D. Metastatic bone disease in the era of bone-targeted therapy: clinical impact. Tumori. 2013;99(1):1-9.

28. Dodwell DJ, Howell A, Morton AR, Daley-Yates PT, Hoggarth CR. Infusion rate and pharmacokinetics of intravenous pamidronate in the treatment of tumour-induced hypercalcemia. Postgrad Med J. 1992;68(800):434-439.

29. Markowitz GS, Appel GB, Fine PL, et al. Collapsing focal segmental glomerulosclerosis following treatment with high-dose pamidronate J Am Soc Nephrol. 2001;12(6):1164-1172.

30. Markowitz GS, Fine PL, Stack JI, et al. Toxic acute tubular necrosis following treatment with zolendronate (Zometa). Kidney Int. 2003; 64(1):281-289.

31. Vaughn CB, Vaitkevicius VK. The effects of calcitonin in hypercalcemia in patients with malignancy. Cancer. 1974;34(4):1268-1271.

32. Warrell RP Jr, Bockman RS, Coonley CJ, Isaacs M, Staszewski H. Gallium nitrate inhibits calcium resorption from bone and is effective treatment for cancer-related hypercalcemia. J Clin Invest. 1984;73(5): 1487-1490.

33. Devogelaer JP, Lambert M, Boland B, Godfraind C, Noel H, Nagant de Deuxchaisnes C. 1,25-Dihydroxyvitamin D-related hypercalcemia in lymphoma: two case reports. Clin Rheumatol. 1990;9(3):404-410.
34. Castellano D, Sepuleda JM, Garcia-Escobar I, Rodriguez-Antolin A, Sundlov A, Cortes-Funes H. The role of RANK-ligand inhibition in cancer: the story of denosumab. Oncologist. 2011;16:136-145.

35. Wada T, Nakashima T, Hiroshi N, et al. RANK-L-RANK signaling in osteoclastogenesis and bone disease. Trends Mol Med. 2006;12: $17-25$.

36. Eastell R, Christiansen C, Grauer A, et al. Effects of denosumab on bone turnover markers in postmenopausal osteoporosis. J Bone Miner Res. 2011;26(3):530-537.

37. Bone HG, Bolognese MA, Yuen CK, et al. Effects of denosumab treatment and discontinuation on bone mineral density and bone turnover markers in postmenopausal women with low bone mass. J Clin Endocrinol Metab. 2011;96:972-980.

38. Brown-Glaberman U, Stopeck AT. Role of denosumab in the management of skeletal complications in patients with bone metastases from solid tumors. Biologics. 2012;6:89-99.

39. Gossai N, Hilgers MV, Polgreen LE, Greegard EG. Critical hypercalcemia following discontinuation of denosumab therapy for metastatic giant cell tumor of bone. Pediatr Blood Cancer. 2015;62:1078-1080.

40. Boyce AM, Chong WH, Yao J, et al. Denosumab treatment for fibrous dysplasia. J Bone Miner Res. 2012;27:1462-1470.

41. Bech A, de Boer H. Denosumab for tumor-induced hypercalcemia complicated by renal failure. Ann Intern Med. 2012;156(12):906-907.

42. Chen C-L, Chen N-C, Liang H-L, et al. Effects of denosumab and calcitriol on severe secondary hyperparathyroidism in dialysis patients with low bone mass. J Clin Endocrinol Metab. 2015;100:2784-2792.

43. Cicci JD, Buie L, Bates J, van Deventer H. Denosumab for the management of hypercalcemia of malignancy in patient with multiple myeloma and renal dysfunction. Clin Lymphoma Myeloma Leuk. 2014;14(6): e207-e211.

44. Cummings SR, San Martin J, McClung MR, et al. Denosumab for prevention of fractures in postmenopausal women with osteoporosis. N Engl J Med. 2009;361(8):756-765.

45. Hu MI, Glezerman IG, Leboulleux S, et al. Denosumab for treatment of hypercalcemia of malignancy. J Clin Endocrinol Metab. 2014;99(9):3144-3152.

46. Dietzek A, Connelly K, Cotugno M, Bartel S, McDonnell AM. Denosumab in hypercalcemia of malignancy: a case series. $J$ Oncol Pharm Pract. 2015;21(2):143-147.

47. Adhikaree J, Newby Y, Sundar S. RE: denosumab for patients with persistent or relapsed hypercalcemia of malignancy despite recent bisphosphonate treatment. J Natl Cancer Inst. 2015;107(3):509.

48. Tong CV, Hussein Z, Noor NM, Mohamad M, Ng WF. Use of denosumab in parathyroid carcinoma with refractory hypercalcemia. $Q \mathrm{~J}$ Med. 2015;108:49-50.

49. Fountas A, Andrikoula M, Giotaki Z, et al. The emerging role of denosumab in the long-term management of parathyroid carcinoma-related refractory hypercalcemia. Endocr Pract. 2015;21(5):468-473.

50. Karuppiah D, Thanabalasingham G, Shine B, et al. Refractory hypercalcaemia secondary to parathyroid carcinoma: response to high-dose denosumab. Eur J Endocrinol. 2014;171:K1-K5.
Orphan Drugs: Research and Reviews

\section{Publish your work in this journal}

Orphan Drugs: Research and Reviews is an international, peer-reviewed, open access journal publishing original research, reports, reviews and commentaries on all areas of the design and development of orphan drugs for the treatment of rare diseases through to clinical applications. Clinical outcomes, patient safety, and programs for the development and

\section{Dovepress}

effective, safe, and sustained use of medicines will be a feature of the journal. The manuscript management system is completely online and includes a very quick and fair peer-review system, which is all easy to use. Visit http://www.dovepress.com/testimonials.php to read real quotes from published authors. 